Наукоёмкие технологии электро-физикохимической и комбинированной обработки

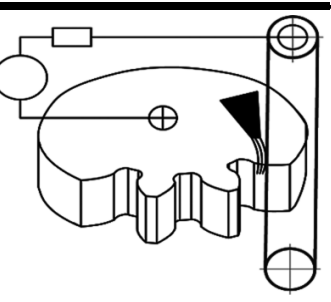

УДК 621.787.6.004

DOI: 10.30987/article_5c90a5967b4a96.85979387

\begin{abstract}
А.В. Киричек ${ }^{1}$, д.Т.н., Д.Л. Соловьев ${ }^{2}$, д.Т.н., С.А. Силантьев ${ }^{2}$, к.Т.Н., С.О. Федонина ${ }^{1}$, аспирант ('ФГБОУ ВО «Брянский государственный технический университет», 241035, Россия, г. Брянск, бул. 50 лет Октября, 7, ${ }^{2}$ Муромский институт (филиал) ФГБОУ ВО «Владимирский государственный университет имени А.Г. и Н.Г. Столетовых», 602264, Владимирская область, г. Муром, ул. Орловская, д.23)

E-mail: ntk_2005@rambler.ru

\section{Влияние процесса упрочнения волной деформации на микроструктуру материала}

В статье представлены результаты исследований влияния комбинированного упрочнения на изменения микроструктуры материала. На основе проведенных исследований описано влияние процесса упрочнения волной деформации на микроструктуру материалов на примере хромо-никелевых легированных сталей. Показано, что комбинированное упрочнение ХТО+ППД обеспечивает повышение механических свойств материала.
\end{abstract}

Ключевые слова: упрочнение; поверхностный слой; волновое деформационное упрочнение; микроструктура.

A.V. Kirichek ${ }^{1}$, Dr. Sc. Tech., D.L. Soloviyov ${ }^{2}$, Dr. Sc. Tech., S.A. Silantiev ${ }^{2}$, Can. Sc. Tech., S.O. Fedonina ${ }^{1}$, Post graduate student ( ${ }^{1}$ FSBEI HE "Bryansk State Technical University", 7, 50 Years of October Boulevard, Bryansk, Russia, 241035

${ }^{2}$ Murom Institute (Branch) FSBEI HE "Vladimir State University", 23, Orlovskaya Str, Murom, Vladimir Region, 602264)

\title{
Impact of wave deformation strengthening process upon material micro-structure
}

The paper reports the investigation results of combined strengthening impact upon material micro-structure changes. On the basis of the investigations carried out there is described an impact of wave deformation strengthening process upon material micro-structure by the example of chromium-nickel alloyed steels. It is shown that ChTT+SPD strengthening ensures the increase of material stress-strain properties.

Keywords: strengthening; surface layer; wave deformation strengthening; micro-structure.

В настоящее время известно много способов упрочнения поверхностного слоя деталей машин. Наиболее часто применяется термическая обработка (ТО), химико-термическая обработка (XTO), горячее изостатическое прессование и поверхностное пластическое деформирование (ППД).

ППД позволяет упрочнить поверхностный слой до 6500 МПа на глубину до 10 мм. Из всего многообразия видов ППД наиболее широкими технологическими возможностями обладает статико-импульсный метод упрочнения поверхности волной деформации, форми- рующейся в ударных системах с промежуточным звеном - волноводом [3].

Для волнового деформационного упрочнения (ВДУ) используется генератор импульсов, основными элементами которого является боек и волновод. При упрочнении боек ударяет по волноводу, статически поджатому к упрочняемой поверхности. В результате в ударной системе боек-волновод генерируются плоские акустические волны, которые характеризуются законом изменения сил во времени, максимальным значением сил, временем действия сил (длительностью) и энергией волны де- 
формации [5]. Эти характеристики, в основном, зависят от геометрии соударяющихся бойка и волновода, свойств их материалов и скорости соударения, рис. 1.

\section{Схема упрочнения волной деформации:}

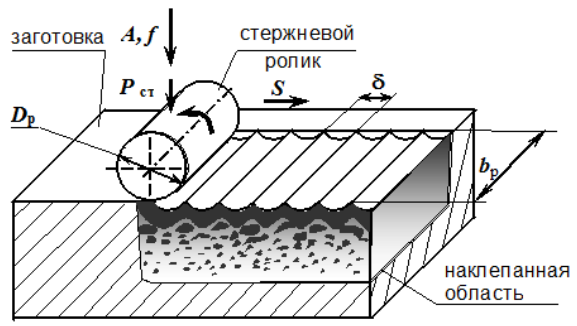

Рис. 1. Упрочнение ударными волнами деформации

В отличие от других методов динамического воздействия, волна деформации проходит через промежуточное звено - волновод, формируя пролонгированный импульс. Таким образом, при среднем значении амплитуды увеличивается энергия и длительность, что позволяет обеспечивать высокий КПД (более 38 \%), а также заданную картину распределения микротвердости и остаточных напряжений в поверхностном слое материала $[1,2]$.

Для оценки влияния параметров упрочнения на микроструктуру материала выполнена серия экспериментальных исследований на примере легированных сталей марок $10 \mathrm{XCHД}$ и $15 \mathrm{XC} 2 \mathrm{H} 2 \Gamma$.

В ходе исследований установлено, что твердость упрочненных образцов стали $10 Х \mathrm{XHД} \mathrm{в} \mathrm{1,5} \mathrm{-} 2$ раза больше по сравнению с неупрочненным образцом, в то время как величина ударной вязкости упрочненного образца уменьшалась не более, чем на $30 \%$ [5]. В результате сочетания деформационного и химико-термического механизма упрочнения обеспечивается повышение микротвердости в 3,5 раза, что объясняется изменением структурного строения металлов.

Под действием внешнего силового упрочняющего воздействия зерна дробятся, по межзеренным границам на большую глубину и с более высокой скоростью диффундируют атомы углерода в процессе цементации, что способствует увеличению глубины упрочненного слоя и положительно влияет на долговечность и ресурс изделия.

Ранее [4] проводились исследования по подбору оптимальных режимов упрочнения без ППД. Образцы из сталей 10ХСНД и $15 \mathrm{XC} 2 \mathrm{H} 2 \Gamma$ подвергались термической и химико-термической обработке: цементации, закалке, отпуску. Образцы цементировались с двух сторон при одинаковой температуре, но с разной выдержкой. Применялась закалка на масло двух видов: в одинаковом температурном интервале при непрерывном охлаждении и ступенчатая, после чего образцы подвергали низкотемпературному и среднетемпературному отпуску.

В ходе первой части исследования установлена высокая эффективность применения ступенчатой закалки, а также применение низкого отпуска. Упрочненный слой в образцах легированных сталей характеризуется несколькими зонами с разными структурными составляющими. Микроструктура подповерхностного слоя мелкозерниста и равномерна на протяжении 29...300 мкм вглубь материала в зависимости от времени цементации детали. Глубже - мартенситная структура с фазовыми элементами разных размеров.

В начале мартенситной зоны иглы мартенсита имеют маленький размер и большую плотность упаковки. В сердцевине цементованного слоя иглы крупные, плотность упаковки существенно ниже. Наибольшие по размеру иглы мартенсита наблюдаются в образцах, цементируемых большее время. К границе цементованного слоя иглы уменьшаются в размерах, а их плотность увеличивается. Однако в образцах, цементируемых в течение большего времени (15 ч), нет зоны игольчатого мартенсита - структура равномерна и мелкозерниста. При двустороннем упрочнении образцов структуры обеих сторон идентичны.

Однако в некоторых образцах из стали 10ХСНД, подверженных среднетемпературному отпуску, мелкозернистая структура подповерхностного слоя переходит в сорбитную структуру с разной длиной полос. Аналогично образцам с мартенситной структурой, полосы сорбита, расположенные глубже подповерхностной зоны имеют небольшую длину и большую плотность упаковки, увеличиваясь к сердцевине упрочненного слоя, плотность упаковки уменьшается.

Ближе к границе цементованного слоя полосы сорбита уменьшаются в размерах, увеличивается плотность их упаковки, переходя в структуру сердцевины образца. В образцах из стали $15 \mathrm{XC} 2 \mathrm{H} 2 \Gamma$ сорбитная структура присутствует во многих образцах, подверженных низкотемпературному отпуску. Такие образцы характеризуются средними значениями ударной вязкости и микротвердости, что не отвечает предъявляемым требованиям об обеспечении высокой твердости упрочненного слоя при значительных показателях ударной вязкости. 

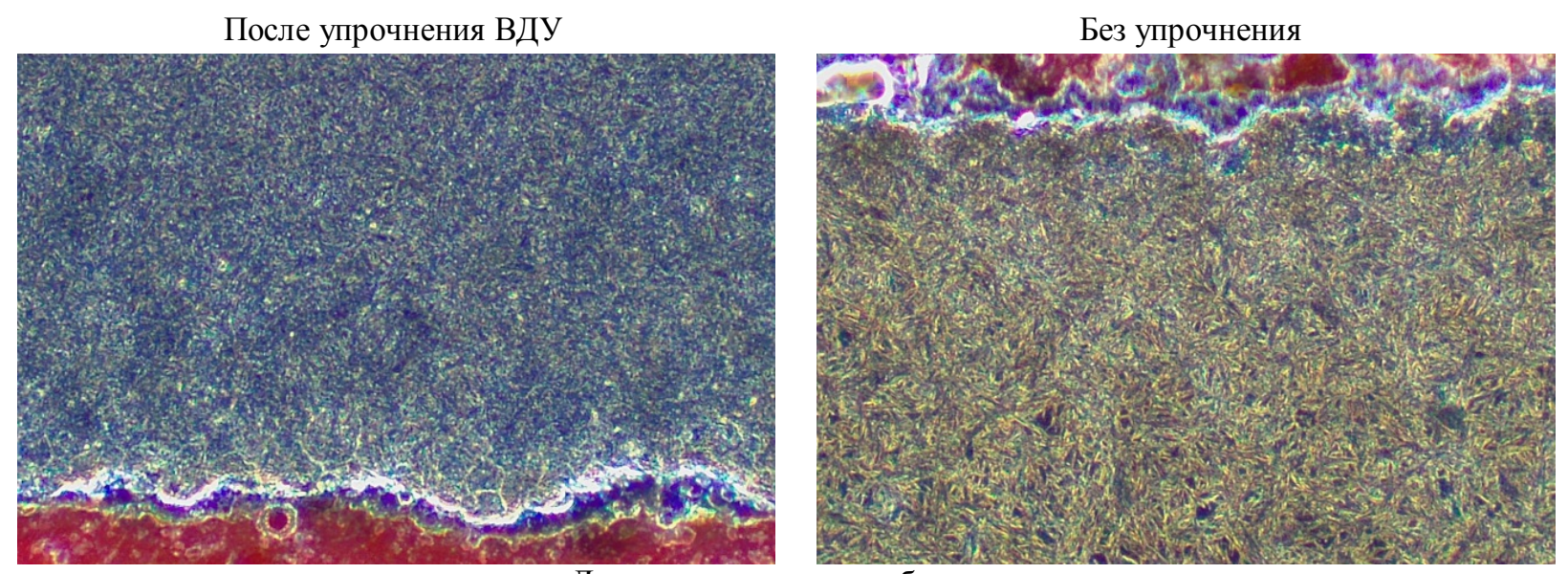

Лицевая поверхность образцов
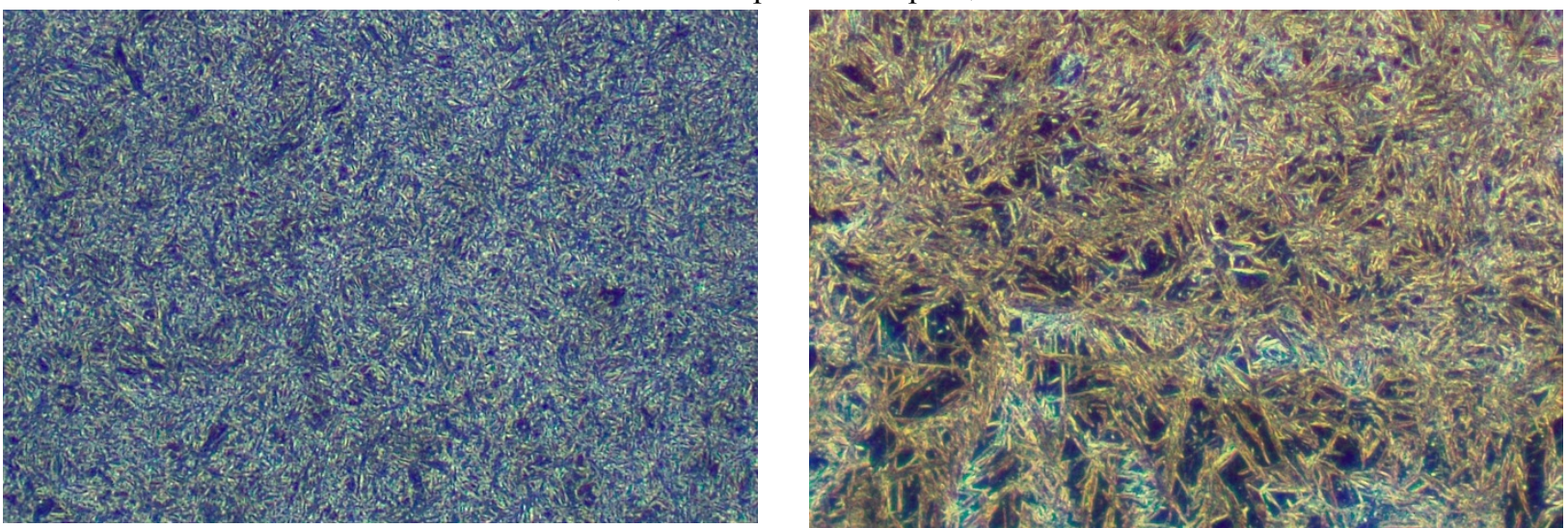

Мартенстная зона, глубина 200...500 мкм
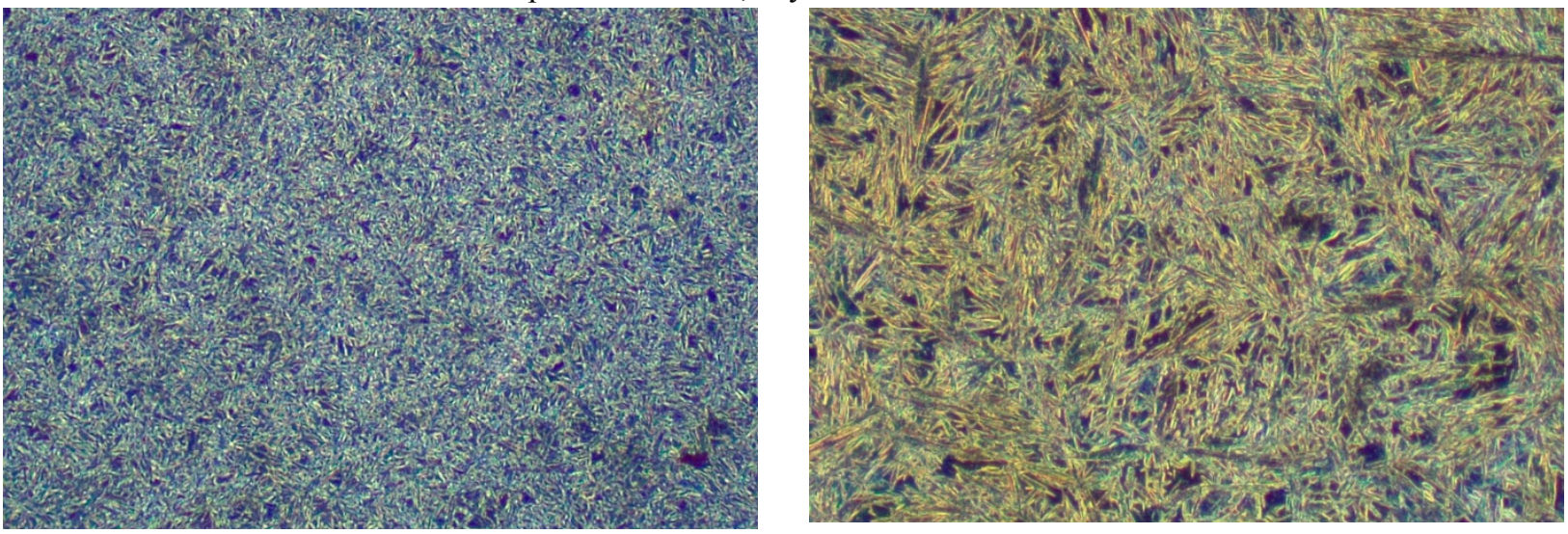

Мартенстная зона, глубина 1400...1800 мкм
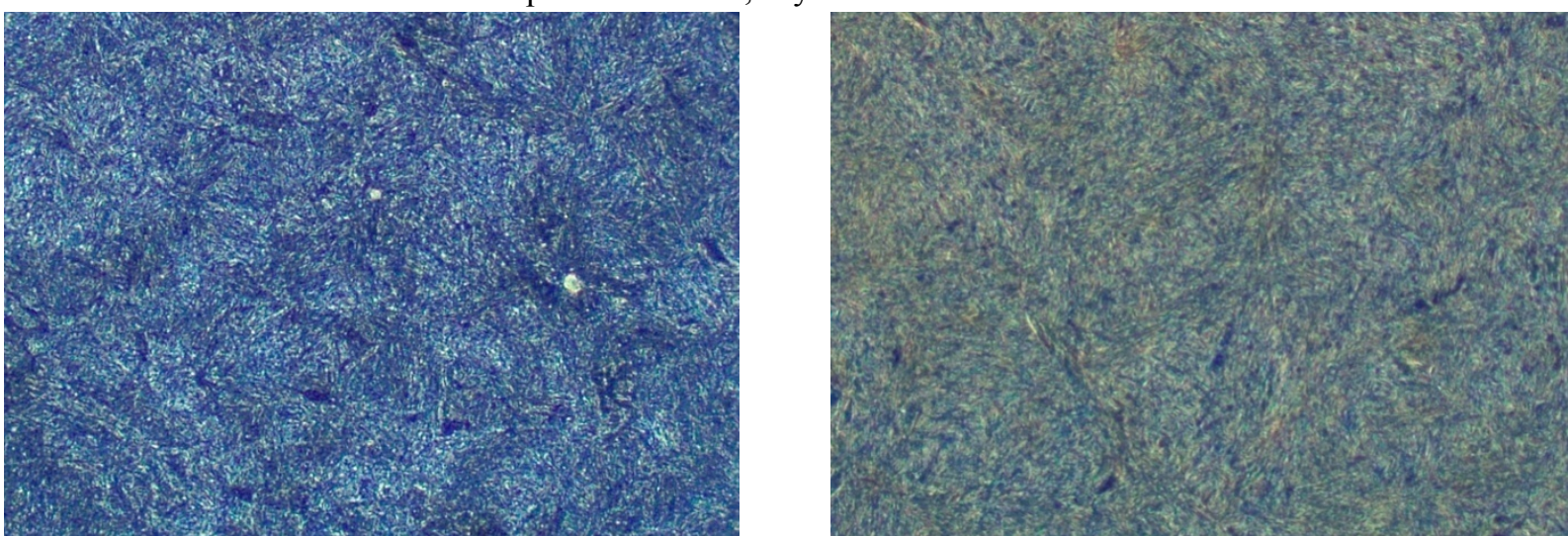

Сердцевина образца

Рис. 2. Микроструктура образца из стали 15 ХС2Н2Г после упрочнения $(\times 2550)$ 
В результате проведенных экспериментальных исследований выявлена комбинированная микроструктура с несколькими видами структурных составляющих: в подповерхностном слое - мелкодисперстный мартенсит отпуска, в центре цементованного слоя - пластинчатая мартенситная структура с оптимальным размером игл мартенсита, обеспечивающим высокие показатели твердости порядка $60 \mathrm{HRC}$ и одни из максимальных параметров ударной вязкости среди исследуемых образцов.

На основе полученных данных проведена вторая часть исследований - упрочнение термообработанных образцов из сталей статикоимпульсной обработкой. Обработка ВДУ проводилась за два прохода с использованием разных коэффициентов перекрытия отпечатков и разной кратности ВДУ, при неизменной геометрии соударяющихся бойка и волновода.

В результате проведенных испытаний экспериментально установлены режимы ВДУ, обеспечивающие наилучшее сочетание степени упрочнения и ударной вязкости, производительности и долговечности детали в целом.

Микроструктура образцов из легированных сталей в результате упрочнения волной деформации имеет более мелкое, равномерно ориентированное зерно на глубине около $350 . .570$ мкм (рис. 2). Глубже расположена структура мелкоигольчатого плотно упакованного мартенсита, не изменяющаяся до глубины $1000 \ldots 1800$ мкм в зависимости от режимов упрочнения. Затем формируется структура, близкая к равномерной структуре сердцевины образца.

Сравнение микроструктуры упрочненного ВДУ и ХТО образца из стали $15 \mathrm{XC2H} 2 \Gamma$ с образцом только ХТО показало:

1) увеличение глубины упрочняемого слоя на $20 \ldots 30 \%$;

2) увеличение глубины мелкозернистой структуры в среднем в 2,0-2,5 раза;

$3)$ уменьшение размера и плотности структурных составляющих сердцевины упрочняемого слоя;

4) более плавный переход микроструктуры сердцевины упрочненного слоя к равномерной микроструктуре сердцевины образца.

Эти измерения в микроструктуре обеспечивают более плавную картину распределения микротвердости в упрочненном образце.

Таким образом, в ходе исследований выявлены следующие преимущества применения в одной технологической схеме деформацион- ного и химико-термического механизма упрочнения:

- увеличение микротвердости (твердости по Виккерсу) упрочненных образцов в $1,5 \ldots 2,0$ раза по сравнению с не упрочненным образцом;

- уменьшение ударной вязкости на $30 \%$ после ВДУ и на 60 \% в результате ВДУ+ХТО;

- увеличение предела прочности в $1,5-1,7$ раза; предела текучести - в 1,5 - 2 раза. Следует отметить сохранение на достаточно высоком уровне ударной вязкости материала при достигнутых значениях пределов прочности и текучести, что благоприятно сказывается на эксплуатационных свойствах изделий.

Полученные результаты позволяют рекомендовать комбинированную технологию упрочнения ВДУ+ХТО для повышения механических свойств легированных сталей хромоникелевой группы.

\section{БИБЛИОГРАФИЧЕСКИЙ СПИСОК}

1. Киричек, А.В., Соловьев, Д.Л. Изменения наноструктуры железоуглеродистых сплавов в результате воздействия деформационных ударных волн. // Журнал нанои электронной физики. 2013. T.5. №4. PART1. С.04009-104009-4.

2. Kirichek, A.V. Determination of the energy parameters of the shock mechanism user to harden the surface by plastic deformation. Applied Mechanis and Materials. 2015. T.756. C. 85-91.

3. Киричек, А.В., Соловьев, Д.Л., Алтухов, А.Ю. Деформационно-волновое упрочнение металлических материалов. // Журнал нано- и электронной физики. 2014. Т.5. №6 С.03069-1-03069-4.

4. Киричек, А.В., Соловьев, Д.Л., Хандожко, А.В., Силантьев, С.А., Федонина, С.О., Маслюков, В.А., Шмат, А.С. Исследование влияния параметров упрочнения на структурные составляющие материала // Наукоемкие и виброволновые технологии обработки деталей высокотехнологичных изделий: Материалы международного научного симпозиума технологов-машиностроителей. Ростов-на-Дону, 26-28 сентября. - 2018. - С. 277-282.

5. Киричек, А.В. Соловьев, Д.Л., Хандожко, А.В., Федонина, С.О. Технологическое обеспечение параметров несущего слоя деформационным и комбинированным упрочнением // Наукоемкие технологии в машиностроении. - 2018. - №10(88). - С.43-48.

\section{REFERENCES}

1. Kirichek, A.V., Soloviyov, D.L. Nano-structure changes in iron-carbon alloys caused by impact of deformation percussion waves. Journal of Nano- and Electronic Physics. 2013. Vol. 5. No.4. PARTI. - pp. 04009-1-04009-4. 
2. Kirichek, A.V. Determination of the energy parameters of the shock mechanism user to harden the surface by plastic deformation. Applied Mechanics and Materials. 2015. Vol.756. - pp. 85-91.

3. Kirichek, A.V., Soloviyov, D.L., Altukhov, A.Yu. Metal deformation-wave strengthening. Journal of Nano- and Electronic Physics. 2014. Vol.5. No.6 pp. 03069-1-03069-4.

4. Kirichek, A.V., Soloviyov, D.L., Khandozhko, A.V., Silantiev, S.A., Fedonina, S.O., Maslyukov, Shmat, A.S. Investigation of strengthening parameters impact upon material structural constituents // Science Intensive and Vibration-Wave
Technologies of Parts Machining for High-Tech Products. Proceedings of the Inter. Symposium of TechnologistEngineering Workers. - Rostov-upon-Don, September 26-28, 2018. - pp. 277-282.

5. Kirichek, A.V., Soloviyov, D.L., Khandozhko, A.V., Fedonina, S.O. Technological support of carrying layer parameters by deformation and combined strengthening // Science Intensive Technologies in Mechanical Engineering. - 2018. No. 10 (88). - pp. 43-48.

Рецензент д.т.н. С.А. Зайдес

УДК 621.9.048.6

DOI: $10.30987 /$ article 5c90a596bf6679.61270022

С.И. Агапов, д.т.н.,

Ю.И. Сидякин, д.Т.н.,

А.Ф. Толстяков, аспирант

(Волгоградский государственный технический университет, 400050 г. Волгоград, проспект им. В.И. Ленина, 28)

E-mail: techmach@vstu.ru

\section{Научно обоснованное повышение надежности пьезоэлектрических преобразователей для ультразвуковой обработки зубчатых колес}

Рассмотрены вопросы раџиональных условий сборки и настройки пьезоэлектрических преобразователей, а также вопросы расчета мощности ультразвукового генератора на примере экспоненциального концентратора с присоединенной заготовкой при зубонарезании мелкомодульных зубчатых колес.

Ключевые слова: пьезоэлектрический преобразователь; экспоненциальный концентратор; мощность ультразвукового генератора.

S.I. Agapov, Dr. Sc. Tech.,

Yu.I. Sidyakin, Dr. Sc. Tech.,

A.F. Tolstyakov, Post graduate student

(Volgograd State Technical University, 28, Lenin Avenue, Volgograd, 400050)

\section{Scientifically substantiated increase of piezoelectric transformer reliability of cog-wheel ultrasonic machining}

The paper reports the consideration of efficient conditions for assembly and adjustment of transformers and also the problems of power calculation for an ultrasonic generator by the example of an exponential concentrator with an attached blank during fine-grained cog-wheel gear cutting.

Keywords: piezoelectric transformer; exponential concentrator; capacity of ultrasonic generator.

При резании труднообрабатываемых материалов сталкиваются с целым рядом трудностей. Одним из наиболее эффективных способов лезвийной обработки является введение в зону резания ультразвуковых колебаний (УЗК) с частотой 18...22 кГц.

Введение УЗК в зону резания возможно от магнитострикционного преобразователя и пьезоэлектрического преобразователя. Применение магнитострикционного преобразователя требует подвода охлаждающей жидкости. Если магнитострикционный преобразователь вращается, то требуется установка уплотнителей, что снижает его надежность. Следует 